

\section{Website accessibility: a survey of local e-government websites and legislation in Northern Ireland.}

Paris, M. (2006). Website accessibility: a survey of local e-government websites and legislation in Northern Ireland. Universal Access in the Information Society, 4(4), 292-299. https://doi.org/10.1007/s10209-003-0081-7

Link to publication record in Ulster University Research Portal

\section{Published in:}

Universal Access in the Information Society

Publication Status:

Published (in print/issue): 01/05/2006

DOI:

10.1007/s10209-003-0081-7

\section{Document Version}

Publisher's PDF, also known as Version of record

\section{General rights}

Copyright for the publications made accessible via Ulster University's Research Portal is retained by the author(s) and / or other copyright owners and it is a condition of accessing these publications that users recognise and abide by the legal requirements associated with these rights.

\section{Take down policy}

The Research Portal is Ulster University's institutional repository that provides access to Ulster's research outputs. Every effort has been made to ensure that content in the Research Portal does not infringe any person's rights, or applicable UK laws. If you discover content in the Research Portal that you believe breaches copyright or violates any law, please contact pure-support@ulster.ac.uk. 


\section{Maeve Paris \\ Website accessibility: a survey of local e-government websites and legislation in Northern Ireland}

\begin{abstract}
The provision of accessible websites is a legal requirement under the Disability Discrimination Act 1995, which applies throughout Great Britain and Northern Ireland, and the Equality (disability, etc.) (Northern Ireland) Order 2000. A survey of local e-government websites indicated that few local councils in the devolved administration of Northern Ireland offered websites which were adequately usable by people with a disability, yet most citizen-government transactions occur at the local level. Design for all has obvious commercial benefits, but it has also become a legal obligation, and application of accessible design principles should improve the online experience of all users.
\end{abstract}

Keywords Web accessibility - Local e-government · Northern Ireland

\section{Introduction}

Accessibility is one of the core principles on which the World-Wide Web was founded. Tim Berners-Lee wrote of the "principles of universality of access irrespective of hardware or software platform, network infrastructure, language, culture, geographical location, or physical or mental impairment' [2]. In the UK, website accessibility is also a legal requirement, and the provision of accessible sites for disabled users is a particular concern of local government, since the majority of citizen-government transactions take place at local government level [18]. In Northern Ireland, where the devolved administration is still suspended despite elections in 2003, few local government websites meet minimum accessibility

M. Paris

School of Computing and Intelligent Systems,

University of Ulster, Magee Campus, Londonderry,

$\mathrm{N}$ Ireland, BT487JL, UK

E-mail: m.paris@ulster.ac.uk

Tel: $+44-2871-375212$

Fax: +44-2871-375470 standards. Starting with a definition of accessibility as it relates to the World-Wide Web, this paper considers local e-government in Northern Ireland in a period of suspended devolution, and presents a survey of local e-government service provision. Local government sites have assumed even greater importance in the current political context, yet many of the sites examined proved to be inaccessible. Designing accessible websites is no longer an optional extra: it is a legal requirement, although no cases have been brought before UK courts, and failure to comply with de facto standards (namely, the standards embodied in the Web Accessibility Initiative's (WAI) web content accessibility guidelines [21]) may compound the existing digital divide for the many disabled people in the province [19]. Not only is Internet access difficult for such communities, but there is the additional problem of inaccessible sites. Reasons for the current situation are offered, as well as suggestions for improvement.

\section{Website accessibility}

The concept of accessibility is at the heart of the Internet; the World-Wide Web consortium (W3C) envisaged a platform-independent system open to everyone: 'the power of the Internet is in its universality. Access by everyone regardless of disability is an essential aspect' [20]. Accessibility is concerned with making information on websites available to the widest audience possible; while this includes users with disabilities, application of accessible design principles should improve the online experience of all users[12]. Design for all has obvious commercial benefits, but it has also become a legal obligation. Internet access for people with disabilities offers many challenges, since it concerns a range of visual, hearing, physical, speech, cognitive and neurological impairments. Guidelines for the implementation of accessible websites have been developed by the W3C, and the US Federal Government. These guidelines overlap, although they differ in some respects, and a comparison 
can be found in [11]. The concept of website accessibility extends beyond websites, to encompass applications, browsers, media players, authoring tools, and evolving technologies.

When applied to software and technology, accessibility is a subset of usability, which is an attribute of software quality. Usability is defined by the International Standards Organisation (ISO) as 'the effectiveness, efficiency and satisfaction with which specified users achieve specified goals in particular environments' [10]. Standards and metrics have been developed to quantify the usability of products, user interfaces and interaction, process quality, and organisational capability. Usability conventions relate to the ease with which users can accomplish tasks and recover from errors; they also relate to provisions for meeting the needs of disabled users. For computers and software applications, accessibility relates to the usability of a computer system by people with disabilities. The ISO defines accessibility as "the usability of a product, service, environment or facility by people with the widest range of capabilities' [9]. This standard offers guidance on the development of accessible software and interactive systems for people with the widest range of visual, hearing, motor and cognitive abilities (including the elderly, and those with temporary disabilities), and is intended to complement general design standards for usability.

Accessibility offers benefits to disabled users, including independence, as it provides quick, easy, and cheap access to services and information, as well as broadening the range of employment and leisure activities. It also allows people with a disability to take part in many activities that most people take for granted such as purchasing gifts, and has knock-on benefits for many different users in the same way as wheelchair ramps, for example, can be used by people with pushchairs [16]. In addition, the availability of online information can empower disabled people who would otherwise be denied access to more traditional forms of communication [7].

\subsection{Local e-government in Northern Ireland}

The relevance of local government to the citizen can be quantified: the office of the UK e-Envoy estimated that there are 5-6 billion annual government-related transactions [15] and the majority of citizen-government transactions ( 4 billion, or $80 \%$ ) take place at the local government level [18]. There are 26 district councils in Northern Ireland, and while they share some of the duties of councils in the rest of the UK ('roads, rates and rubbish'), they are more limited in scope. The main areas under council control are community services, building control, dog licensing, environmental health, housing fitness and standards, leisure and parks, refuse collection and waste disposal, registration of births, deaths and marriages, and street naming and postal numbering. Northern Ireland councils are responsible for only $4 \%$ of public expenditure, while councils in Wales, for example, account for $46 \%$ of total expenditure. The gap in expenditure is filled by non-departmental public bodies and quangos. Consequently, councils in Northern Ireland can be considered less powerful than their counterparts in Wales or Scotland [1].

It is difficult to ascertain the extent to which e-government has been a high priority for Northern Ireland. Certainly, all initiatives and strategies emanating from the Northern Ireland Assembly relate to the electronic provision of services at the level of the devolved administration: there is no linkage drawn with local council initiatives, and this is in stark contrast to the UK central government approach. The first Northern Ireland Executive Programme for government suggested in vague terms that Executive Programme Funds (EPFs) might be available to cover certain policy issues in relation to service modernisation: 'actions that might be included are e-government...'[13]. No further specification was provided, although there was a commitment to develop these actions in the corporate strategic framework for delivering government services electronically in Northern Ireland, which was published by the Central IT Unit (NI) in 2001 [4].

This framework was citizen-focused and pledged to ensure consistency and integration with central government initiatives. Although the framework applied explicitly to the core Northern Ireland Civil Service Departments, it was intended to be 'applicable to the entire public sector in Northern Ireland' [4]. The section in the framework of most interest to this study relates to connecting with the citizen or business, 'improving the way in which government interacts with its customers, and meets their needs'. For the Northern Ireland Assembly, this presented an opportunity for modification of the Prime Minister's 2005 target: 'in keeping with the principle that services should be designed around the needs of citizens (rather than the organisation) departments will be identifying those interactions which if delivered electronically would significantly improve the quality, effectiveness and responsiveness of government services' [4]. In other words, not all services would be implemented fully by 2005 ; instead, 'key' services would go online. Northern Ireland was taking a very different approach. So, in July 2001 the Executive Committee approved electronic service delivery targets to deliver $25 \%$ of key Government services electronically by the end of 2002 , with $100 \%$ capability by 2005 . No mention was made of the applicability of this target to local government.

The question arises of how one can define a 'key' service. Definitions were formally provided much later in a set of Guidelines for the Initiation of e-government pilot projects published by the CITU(NI) in 2003 [5]: criteria included those services which resulted in a high number of transactions (such as road fund licences), services which might be highly valued by users (such as payment of rates), and services which are obligatory public sector transactions (such as notifying agencies of address changes), although this was open to interpretation: discretion was left to each department. 
By 2002, it was possible to identify the existence of a digital divide in the province. Although Northern Ireland could be considered successful in terms of enabling e-business, for the citizen the picture is rather different: the digital divide has left $53 \%$ of citizens at a disadvantage, and particular groups affected include disabled people, those over 50 and the lower-earning socio-economic groupings. The 2002 report recognised that this digital divide was a barrier to citizens' enjoyment of electronic delivery of government services [19]. So, disabled people are less likely to have access to the Internet in the first instance, and where they do have access, they may face the additional problem of inaccessible websites.

Devolution was suspended in Northern Ireland at midnight on 14 October 2002, and at that time elections to the Northern Ireland Assembly were suspended. Fresh elections were held on 26 November 2003, although these elections did not result in the Assembly being re-constituted, so the political process has stalled again. From 2002, the Secretary of State assumed responsibility for the 11 Ministerial departments, assisted by a group of Northern Ireland Office ministers. With little movement at the level of the devolved administration, the focus moved to local government. This ongoing situation means that local government websites provide the only direct form of communication with the citizens of Northern Ireland.

\subsection{Local e-government and the Disability Discrimination Act}

It has been estimated that the proportion of disabled people in Northern Ireland is one in six of the population [8]. Disability discrimination law is enforced by the Equality Commission for Northern Ireland (ECNI), which is an independent body set up under the Good Friday Agreement. The Commission's remit also includes responsibility for the elimination of discrimination, the promotion of equal opportunities, and the encouragement of good practice in treatment of people with a disability. Two pieces of legislation offer protection against discrimination on the grounds of disability: the Disability Discrimination Act 1995 (DDA), which applies throughout Great Britain and Northern Ireland, and the Equality (disability, etc.) (Northern Ireland) Order 2000.

Most of the DDA applies in Northern Ireland (with the exception of the rules governing education), subject to certain adaptations. However, any changes to the DDA are now within the remit of the Northern Ireland Assembly. This means that the DDA in Northern Ireland will diverge from the DDA in the rest of the UK, since changes made in Northern Ireland do not apply in Westminster, and vice versa. Under the Northern Ireland Act 1998, the Assembly deals with 'transferred matters', including equal opportunity access. As a consequence, the guidance and codes of practice in North- ern Ireland are issued by a different body from the rest of the UK, although at this stage they are largely similar. Public authorities in Northern Ireland have additional special obligations to promote equality of opportunity between many groups of people, including those with a disability as defined by the DDA, and they must devise equality schemes. Special arrangements are in place in the current period of suspended devolution.

The DDA aims to end discrimination against disabled people, by giving them rights in relation to employment, and access to goods, facilities, services, and premises. The DDA makes it unlawful to treat disabled people less favourably than able-bodied people. A person with a disability is defined as having 'a physical or mental impairment which has a substantial or long-term adverse effect on his ability to carry out normal day-today activities'. While the Act extends throughout the UK, there are separate codes of practice for Northern Ireland. The DDA does not make provision for an enforcement body to ensure compliance; hence, the Equality Commission's disability powers were extended through the Equality (disability, etc.) (NI) Order 2000 (EDO). This Order expanded the remit of the ECNI to include the promotion of the equalisation of opportunities for disabled people, and the encouragement of good practice in their treatment, among other duties [8].

The duties of service providers are specified in Part III of the Act, which has come into force in three stages, and relates to the rights of disabled people to have access to services that most people take for granted: since 1996, it has been unlawful to treat a disabled person less favourably for a reason related to the disability (stage one); since 1999, service providers have had to make reasonable adjustments to prevent their arrangements or premises from discriminating against disabled people (stage two); and by 2004, service providers will have had to have made reasonable adjustments to the physical features of their premises to overcome barriers to access (stage three).

The Act makes it unlawful to discriminate against disabled people by refusing to provide any service that is provided to the public in general, or by the standard or terms of a provided service (Sect. 19(1)). The services affected by Part III of the Act include those provided to the public by local councils, and government departments and agencies (Sect. 19(3)). Public authorities in Northern Ireland must comply with the DDA, and they are also subject to Sect. 75 of the Northern Ireland Act (1998), which refers to the need to promote equality of opportunity between people with a disability and those without (equality of opportunity also extends to many areas, including religious beliefs, sexual orientation, gender, and political opinion). Less favourable treatment can be a refusal to provide a service to disabled people, while offering a service to the general public, the provision of a lower standard of service, or failure to make reasonable adjustments so that a disabled person can make use of a service (p. 19). The Act extends to services offered on websites, and the Code of Practice 
makes this explicit (p. 11). An example of a reasonable adjustment includes the library purchase of text to speech software (p. 34).

Reasonable adjustments include changes to practices, policies and procedures, as well as the provision of auxiliary aids and services (Sect. 21). Auxiliary aids and services can often be technological in nature, and they should improve communication, although, in most cases, there is not a single solution, and a variety of aids and services will have to be employed. The Code of Practice makes explicit suggestions: people with a hearing disability would benefit from accessible websites ( $\mathrm{p}$. 51); people with a visual impairment would benefit from readers, documents in large, clear type, and accessible websites (p. 52). The Code in general urges the adoption of an inclusive approach, which makes services available to all in the same way, rather than offering alternatives depending on the disability.

Sloan [17] considered the Act in detail, showing how websites came within the scope of the Act and citing international cases such as Maguire v. SOCOG, which have implications for the UK, but to date no person or company in the UK has been sued for failing to make websites accessible to people with disabilities. This is not to say that it will not happen in the future, but no cases have yet been brought before any UK courts. Sloan [17] observed that this was hardly surprising since the Act and the Code of Practice were designed to encourage the resolution of disputes before they reach the courts. However, the Cabinet Office e-Government Unit indicated that websites are covered by the Act, even though they are not mentioned explicitly; since the Code of Practice makes express reference to websites, and it should be referred to for guidance in Court when deciding on Part III DDA cases, the e-Government Unit anticipated that this would be highly relevant in any course judgement [6]. However, in relation to Northern Ireland, the Equality Commission's most recent report [7] made no direct reference to websites or local government obligations.

\section{Methodology}

A council's website should reflect the standards and principles it espouses, and the home page should make a clear statement about accessibility [22]. Home pages were chosen in the context of the survey reported in this paper for the following reasons: the home page may be the first point of contact a citizen has with local government, and it is the first page a user will arrive at when visiting a council website. A homepage also typically provides useful links for existing users of the site (contacts, maps, etc). One would expect useful and important navigational links (as opposed to splash screens). The homepage is under the direct control of the council. It would not be fair to compare entire websites as they differ so widely in the range of available material. Overall, 26 homepages were examined. As homepages can change rapidly, they were all downloaded on 2 September 2003 in order to ensure uniformity of analysis. Each homepage was analysed individually, and the number and type of accessibility errors on each page was recorded.

One of the standard ways of analysing the accessibility of websites is through the use of the Center for Applied Special Technology's (CAST) Bobby software (http://bobby.watchfire.com/bobby/html/en/index.jsp). Bobby implements the 5 May 1999 version of the WAI web content accessibility guidelines, as well as the US Section 508 Guidelines for accessibility adopted by the Access Board of the US Federal Government. These guidelines have become the de facto standard for measuring website accessibility [16]. While Bobby can automatically assess the level of accessibility of a site, there are some important areas it cannot cover, such as the requirements for text transcriptions for audio files for deaf people. In addition, Bobby advises additional user checks.

If there are no accessibility errors on a website, the Bobby approved icon or the A icon may be displayed. If all but a small number of pages pass Bobby, only those pages which pass may display the icon, or the homepage may display the icon together with a list of those pages which have yet to qualify for Bobby approval. There are different icons depending on the level of accessibility the site achieves: A, AA, AAA or 508; these reflect the three distinct levels proposed in the guidelines: priority 1 or 'A' concerns things which must be done; priority 2 or 'AA' concerns things which should be done; and priority 3 or 'AAA' concerns things which may be done, in order to satisfy accessibility guidelines.

The WAI offers a set of guidelines, but there is currently no fully automatic method for an organisation to validate its website against these guidelines. The Bobby tool is useful for comparison purposes, and should raise awareness of issues which could impede accessibility. There are limitations to this tool: while a Bobby report will highlight issues of concern, it will not correct these; some of its recommendations relate to future technology, and it does not validate a web page. The UK eGovernment guidelines stress that 'getting validation clearances, a successful Bobby test, and a W3C WAI rating does not necessarily guarantee that your site is, e.g., accessible via a screen reader' [14] and they recommend further testing through testers such as the WAVE accessibility checker, Page Valet and the A-Prompt toolkit. However, these guidelines recognise Bobby's position as the leading tool and recommend its use as a starting point. As this survey is concerned with local e-government in the context of Northern Ireland, and hence the United Kingdom, it was considered appropriate to use the tool in line with UK e-government recommendations.

In addition, file sizes of the homepages were measured. File size is not an explicit consideration in the WAI guidelines, so such a measure might be considered of lesser importance than compliance with priority 
checkpoints; however, the UK eGovernment Guidelines $[14,3]$ offer specific recommendations in this regard, advocating a maximum homepage file size of $40 \mathrm{~KB}$, with no image file size to be larger than $30 \mathrm{~KB}$, since larger files take longer to load, and hence are more expensive to users on slow modems. Large homepages are especially disadvantageous, as users do not have the choice of accessing the site through a faster, cheaper route; indeed, the eGovernment Guidelines recommend that developers presume that users are connected through a $28.8 \mathrm{kbit} / \mathrm{s}$ modem when designing pages [14, 3]. Finally, validation was carried out into the syntax of the HyperText Markup Language (HTML) and Cascading Style Sheet (CSS) files, to ascertain code compliance with international standards.

\subsection{Findings}

Twenty-five of the twenty-six local councils had a website (the exception was one council which displayed an index page only and so could be not be analysed fully). Thirteen homepages had links to the external developers who created them, and four of these were created by the same company. Two websites displayed 'best site' awards from the Society of Information Technology Management (SOCITM). Three homepages were essentially splash screens with nothing more than a set of links to other parts of the site. The other council homepages had text information, links, and in many cases, regular news updates and weather. Figure 1 below is a high-level summary of the findings. This Figure illustrates compliance with level 1 (A) guidelines only; there was not even one site which complied with level 2 (AA) or level 3 (AAA) guidelines.

Only one homepage claimed that it was Bobbycompliant to level A and displayed the appropriate icon; however, when it was submitted for analysis, the Bobby report identified one error which meant that the page did

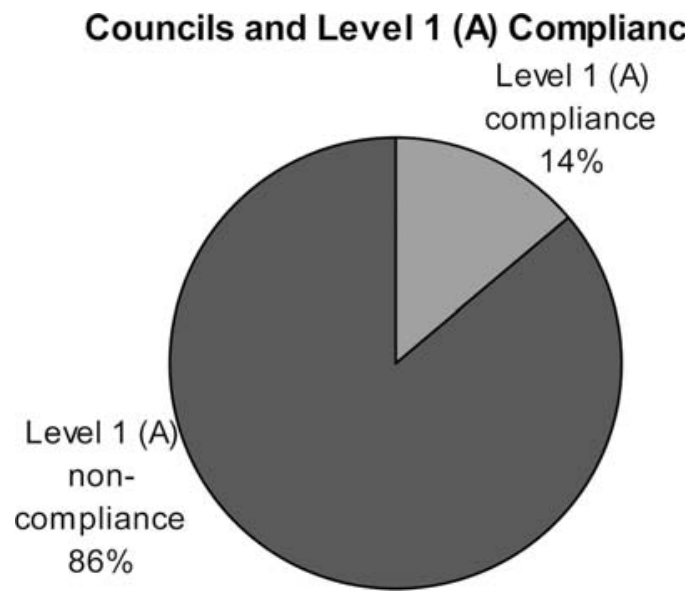

Fig. 1 Councils and level 1 (A) compliance not meet the requirements for $\mathrm{A}$ status, so the page was not entitled to display the icon.

Only one of the homepages had a text-only or accessibility link. Text-only versions of a page are important as they allow a user to employ a screen reader to access the same information as a fully sighted reader. The reader can be text-to-speech or text-to-Braille. The positioning of the link to the text-only version is important, as it is a waste of time if a reader has to go through most of the text before coming on the text-only link. While this website claimed to offer a text-only link, clicking on the hyperlink led to a dead end (a page with the message 'this page cannot be displayed'), making this a further example of misleading information. However, alternative text-only webpages are no longer considered to be best practice, certainly in relation to UK e-government. The eGovernment Guidelines [14] would prefer sites to be fully accessible and usable, rather than providing a usable, accessible text-only alternative. The preferred model is to offer a default, useable site, with links to a multimedia alternative if necessary.

The average size of the homepages was $21.75 \mathrm{~KB}$; two were very compact indeed: at 722 and 752 bytes. However, four websites had file sizes in excess of the maximum recommended by the UK eGovernment guidelines $(40 \mathrm{~KB})$ [14]. The size of the files affects the download time, as larger files take longer to download. Long download times can lead to user frustration.

Level 1 ('A') errors were found in all but four of the twenty-six websites (Table 1).

So, four of the councils were entitled to claim ' $A$ ' status, provided this is supplemented with a recommended list of user checks, although none of these provided an alternative text version of the site, as recommended in the user checks. The most common level one error was the failure to provide alternative text for images, which satisfies the guideline relating to the provision of equivalent alternatives to auditory and visual content (17 sites had this error, and one site had 40 instances of this error on its page). The other errors also related to this guideline: on three occasions there was no alternative text for applets, and several sites neglected to provide alternative text for image map hotspots, image buttons in forms and scripts.

Level 2 ('AA') errors were found in all of the homepages (Table 2):

Twenty-three sites had a common error related to the use of markup and style sheets: they should have used relative rather than absolute units in relation to sizing.

Table 1 Level 1 ('A') errors in council homepages

\begin{tabular}{lll}
\hline $\begin{array}{l}\text { Number of Council } \\
\text { Homepages }\end{array}$ & $\begin{array}{l}\text { Number of level 1 } \\
\text { errors }\end{array}$ & $\begin{array}{l}\text { Percentage } \\
\text { of all councils }\end{array}$ \\
\hline 4 & 0 & 15 \\
14 & 1 & 54 \\
5 & 2 & 19 \\
2 & 3 & 8 \\
\hline
\end{tabular}


Table 2 Level 2 ('AA') errors in council homepages

\begin{tabular}{lll}
\hline $\begin{array}{l}\text { Number of council } \\
\text { homepages }\end{array}$ & $\begin{array}{l}\text { Number of } \\
\text { level 2 errors }\end{array}$ & $\begin{array}{l}\text { Percentage of } \\
\text { all councils }\end{array}$ \\
\hline 1 & 1 & 4 \\
5 & 2 & 19 \\
9 & 3 & 35 \\
8 & 4 & 31 \\
1 & 5 & 4 \\
1 & 6 & 4 \\
\hline
\end{tabular}

Absolute values such as picas, points or inches cannot be resized if they are too small for the reader; units are better specified in relative sizes such as percentages, which the visitor can then adjust. Seventeen homepages failed to create documents which validate to published formal grammars (this is a matter of specifying a DOCTYPE for the Document Type Definition (DTD)). Twelve homepages failed to associate labels with their controls in relation to forms, while ten pages used the same link phrase twice to point to different URLs. Ten pages also failed to ensure that event handlers are device-independent; where an event requires some input from the user, it should not be dependent on one particular device (in practice this tends to mean a mouse), so keyboard equivalents should be provided for mouse events, as these can be voice-activated.

Level 3 ('AAA') errors were also found in all of the homepages (Table 3):

The most common error (found in 23 pages) was a failure to provide a summary for tables: assistive technologies read through all of the content, and if important information is placed at the start of a section, a visitor can decide whether this section is useful without having to go through all of it.

Twenty-two sites failed to identify the primary natural language of the document: this is useful for multilingual visitors using assistive technologies: if language changes are identified, speech synthesisers, for example, can change to the new language. Fifteen sites failed to include non-link printable characters between adjacent links (some assistive technologies cannot differentiate between adjacent links), and ten sites failed to include default place-holding characters in edit boxes and text areas; this is needed to facilitate older user agents. Six sites failed to provide redundant text links for each active region of a client-side image map, which ensures that if the image is not displayed (as is the case with a

Table 3 Level 3 ('AAA') errors in council homepages

\begin{tabular}{lll}
\hline $\begin{array}{l}\text { Number of } \\
\text { council homepages }\end{array}$ & $\begin{array}{l}\text { Number of } \\
\text { level 3 errors }\end{array}$ & $\begin{array}{l}\text { Percentage of } \\
\text { all Councils }\end{array}$ \\
\hline 2 & 1 & 8 \\
5 & 2 & 19 \\
8 & 3 & 31 \\
10 & 4 & 39 \\
\hline
\end{tabular}

text-only browser), the links will still be obvious to visitors.

HyperText Markup Language and CSS validation of the homepages was also carried out through the W3C online markup validation service. This ensures that the code of a webpage is compliant with the standards set by the W3C consortium (http://validator.w3.org). If code is correct (in other words, if it does not contain syntax errors) it should work on multiple browsers and on different platforms; therefore, it should facilitate accessibility. Validation is considered to be one of the quality criteria for a web page (although a valid web page is not necessarily a good quality page, but an invalid page cannot be considered to be a good webpage). Not even one of the pages passed the validation process, so not one of the pages was written in legal HTML. While browsers will try to display pages which are not in legal HTML, different browsers will try to interpret illegal HTML differently, which ultimately leads to lower quality. Many sites had a high number of errors (more than one hundred), although two sites had fewer than ten errors. CSS validation was less problematic. All sites which used style sheets were mainly compliant (with at most one error), although the validator stressed the importance of linking style sheets to legal HTML files.

\subsection{Analysis of findings}

In all, $85 \%$ of local e-government website homepages in Northern Ireland failed to meet the minimum accessibility standards, and $15 \%$ of homepages exceeded maximum recommended file sizes which has implications for download times and user satisfaction. Many of the pages had the same errors; these errors were identified automatically, so it should be possible to automate (or semi-automate) the process of rectifying them. Two websites made false claims in relation to accessibility.

Areas of potential improvement for local e-government service providers were identified in the survey. Some of these could be considered worthy of immediate attention; for example, those relating to minimum compliance. Alternative text provision for images, for example, would ensure level A compliance for a further 14 council homepages. Moving to level 2 or AA compliance would be a relatively simple task for the majority of websites: it would involve a simple rethink of sizing specification, expressed through percentages as opposed to picas or points, and a reference to published formal grammars. AAA compliance could be achieved by some sites through the provision of a summary for tables. None of these remedies could be considered especially costly or time-consuming for developers to implement (especially as many HTML code generators facilitate the alternative text for images, for example).

So, most of the local e-government homepages proved to be inaccessible even at the most basic level of compliance, which leads to two questions: why should this be the case, and what can be done to improve the 
situation? It may be a lack of knowledge or awareness: where websites were developed by local councils themselves, in-house developers might not have been aware of accessibility issues, and the principle of compliance may not be documented in council literature; where sites were developed by external companies, these developers may not have prioritised accessibility, or may not have elicited an accessibility compliance requirement as part of the site specification. There may also be a lack of knowledge about disability rights within the disabled community. Finally, it may be that there are no mechanisms in place to ensure compliance, and no political will to push the issue forward, in the absence of an effective administration in the province. It may be that the peculiar circumstances of the current suspended administration have effectively stalled all progress on such issues and have thus led to Northern Ireland being out of step with the rest of the UK with regards to accessibility. Sloan observed that the Disability Rights Commission in the UK lacked real teeth [17]; it may be that its counterpart in Northern Ireland, the Equality Commission, is similarly hampered.

In order to improve the situation, local councillors need to be made aware of accessibility issues. By focusing awareness at the local e-government level, which is after all where the majority of citizen-government transactions occur, councillors and council officials should be able to press for compliance. Websites developed by external companies should have a level A accessibility requirement, at the very minimum. This requirement has already been introduced for UK e-government websites $[14,3]$. The larger, fundamental problem of suspended devolution and its effect on legislation may be resolved by the end of 2005, in which case further progress could be made on the elaboration of legislation governing accessibility in Northern Ireland.

\section{Conclusions}

Most services of interest to citizens are run by local authorities, but these authorities are not well equipped to provide these services electronically. Very few of the Northern Ireland local e-government websites that were examined in the survey reported in this paper could be considered usable by disabled people. This is not acceptable from a legal perspective; in addition, it goes against the principles on which the World-Wide Web was founded. The DDA applies throughout the UK, although there are different arrangements for promoting and enforcing its implementation in Northern Ireland. E-government websites in the UK must be at least level 1 (A) compliant. In this survey, most Northern Ireland local e-government sites did not achieve this minimum level of compliance. The peculiar political circumstances which pertain in the province (transferred matters were passed to the Northern Ireland Assembly, which is currently suspended) have meant that little progress has been made on disability discrimination matters.
As a first step, local e-government website developers should ensure basic compliance with legal HTML and CSS standards. This would entail routinely validating and correcting code, but would mean that files could then be compatible with different browsers and platforms. This should be part of any requirements specification for local e-government sites. As a second step, the requirement for a minimum level of accessibility should also be specified in all contracts. Thirdly, a campaign to raise awareness of disability issues as they relate to websites would help to raise the profile of accessible websites and impress on local councils the need to build accessibility into all levels of electronic service delivery.

Is the performance of e-government websites worse in Northern Ireland than in the rest of the UK? A leaked internal investigation from the Office of the e-Envoy concluded that $78 \%$ of public sector websites did not meet accessibility standards. (This survey found that $85 \%$ of local e-government websites failed to meet the minimum standards.) As a consequence, the UK government has imposed contractual responsibility to companies building public sector websites to conform to international web accessibility standards [5]. As some of the websites in this survey were built by external companies (and in some cases funded by the European Union through the Regional Development Fund) this policy might be adopted by local councils in Northern Ireland too.

\section{References}

1. Belfast Telegraph (2003) Councils are less powerful than in Wales. Belfast Telegraph

2. Berners-Lee T (1998) Web Architecture from 50,000 feet, http://www.w3.org/DesignIssues/Architecture.html

3. Cabinet Office e-Government Unit (2002) Illustrated handbook for web management teams, http://e-government.cabinetoffice.gov.uk/Resources/WebHandbookIndex1Article/fs/ en?CONTENT ID $=4001529 \& \mathrm{chk}=$ MSHC $8 \mathrm{~g}$

4. Central IT Unit (NI) (2001) Corporate strategic framework for delivering government services electronically in Northern Ireland March 2001, available at: http://www.cituni.gov.uk/ shortcorpdoc.htm.

5. Central IT Unit (NI) (2003) Guidelines for the initiation of egovernment pilot projects, 2003, available at: http://www.cituni.gov.uk/guidelines.pdf.

6. EGovernment News, 11 April 2003 UK government websites criticised europa.eu.nt

7. Equality Commission for Northern Ireland (2004) Disabilty Discrimination Law in Northern Ireland - a short guide

8. Equality Commission for Northern Ireland (2002) Public attitudes to disability in Northern Ireland summary report

9. International Standards Organisation (2003) ISO/TS 16071: ergonomics of human-system interaction-guidance on accessibility for human-computer interfaces

10. International Standards Organisation (1998) ISO 9241-11: guidance on usability

11. Lazar J, Beere P, Greenidge K, Nagappoa Y (2003) Web accessibility in the Mid-atlantic United States: a study of 50 homepages. Universal Access Inf Soc 2:331-341

12. Nielsen J (1996) Accessible design for users with disabilities, http://www.useit.com/alertbox/9610.html 
13. Northern Ireland executive (2001) Programme for government, available at: http://www.ofmdfmni.gov.uk/publications/pfga/ ch1.htm.

14. Office of the e-Envoy (2002) Guidelines for UK government websites: framework for local government, http://www.e-envoy.gov.uk/assetRoot/04/00/21/02/04002102.doc

15. Office of the e-Envoy (2003) Available at:http://www.e-envoy.gov.uk/oee/oee.nsf/sections/briefings-top/\$file/govgateway.htm

16. Owen J (2003) Making your website accessible, Update Jan 2003 http://www.cilip.org.uk/update/issues/jan03/article2jan.html

17. Sloan M (2001) Web accessibility and the DDA. J Inf Law Technol (JILT), vol. 2. http://elj.warwick.ac.uk/jilt/01-2/sloan. html.
18. Socitm (2001) Local e-government now, April 2001

19. The Office of the First Minister and the Deputy First Minister (2002) Bridging the digital divide in Northern Ireland a consultation document, August 2002

20. W3C, http://www.w3.org/WAI/.

21. W3C (1999) Web Content Accessibility Guidelines 1.0, http:// www.w3.org/TR/WCAG10/.

22. Willson R, Bellaby G (2003) SENDA and University homepages. In: 4th Annual Conference of the LTSN Centre for Information and Computer Sciences, Galway 